\title{
Biliary Epithelial Cells from Mice with Congenital Polycystic Kidney Disease Are Hyperresponsive to Epidermal Growth Factor
}

\author{
JEROEN NAUTA, WILLIAM E. SWEENEY, JOE C. RUTLEDGE, AND \\ ELLIS D. AVNER \\ Department of Pediatrics, Sophia Children's Hospital, Rotterdam, The Netherlands [J.N.] and \\ Departments of Pediatrics [J.N., W.E.S., E.D.A.] and Laboratory Medicine [J.C.R.], Children's Hospital \\ Medical Center and the University of Washington School of Medicine, Seattle, Washington 98195
}

\begin{abstract}
Epithelial hyperplasia is an early feature of the renal and biliary lesions in autosomal recessive polycystic kidney disease (ARPKD). To explore the cellular basis of this hyperplasia we isolated, cultured, and characterized biliary tract epithelium from common bile duct explants of mice with ARPKD (the BPK mouse) and controls. Primary cultures resulted in dense colonies of contact-inhibited epithelial cells with a homogenous growth pattern. Colony growth in serum-free basal medium (BM) of BPK-derived cells was not different from controls. Supplementation of BM with epidermal growth factor (EGF) induced a proliferative response in BPK-derived cells that was significantly increased over controls as assessed by $\left[{ }^{3} \mathrm{H}\right]$ thymidine uptake and expressed as percent change over growth in BM (BPK 239\% and controls $131 \%$ of $\mathrm{BM}$ growth). In contrast, no differences between BPK- and control-derived cells were found with regard to the effects of BM supplementation with IGF-I, IGF-II, acidic fibroblast growth factor, keratinocyte growth factor, hepatocyte growth factor, or transforming growth factor- $\beta$. Primary culture of biliary epithelium may provide a useful in vitro model for the study of the cellular pathophysiology of ARPKD. Our data
\end{abstract}

ABSTRACT

demonstrate that increased epithelial sensitivity to EGF-like proteins may play a role in biliary epithelial proliferative changes which parallel renal tubular epithelial proliferation in ARPKD. (Pediatr Res 37: 755-763, 1995)

$\quad$ Abbreviations
PKD, polycystic kidney disease
BM, basal medium
EGF, epidermal growth factor
aFGF, acidic fibroblast growth factor
KGF, keratinocyte growth factor
HGF, hepatocyte growth factor
TGF, transforming growth factor
ADPKD, autosomal dominant polycystic kidney disease
ARPKD, autosomal recessive polycystic kidney disease
EGF-R, epidermal growth factor receptor
DBA, Dolichos biflorus agglutinin
HEPES, $N^{\prime}$-2-hydroxyethylpiperazine- $N^{\prime}$-2-ethanesulfonic acid

Genetically determined PKD affects about one person in thousand and is responsible for significant morbidity and mortality (1). Usually it is the hallmark of a unique autosomal dominant $(\mathrm{ADPKD})$ or autosomal recessive (ARPKD) disorder. The cystic renal tissue is characterized by fluid accumulation in progressively enlarging dilatations of preexisting renal tubules which lead to distortion of renal architecture and ultimately to renal failure. Renal failure develops in about half

Received April 26, 1994; accepted February 20, 1995.

Correspondence and reprint requests: J. Nauta, M.D., Sophia Children's Hospital, Dr. Molewaterplein 60, 3015 GJ Rotterdam, The Netherlands.

Manuscript dedicated to Professor H.K.A. Visser in honor of his retirement.

Supported by the Sophia Foundation for Medical Research in Rotterdam, The Netherlands, the Dutch Kidney Foundation, and grants DK 34891 and DK 44875 from the National Institutes of Health.

A preliminary report of these findings was presented at the 1992 Annual Meeting of the American Society of Nephrology, and has appeared in abstract form (29). of patients with ADPKD and in virtually all those patients with ARPKD who survive the perinatal period (2). ARPKD typically presents perinatally or during the first years of life. Many patients die at birth from pulmonary hypoplasia, which is thought to result from oligohydramnios and inadequate prenatal renal function. In contrast, ADPKD typically is a disease of adults with disease manifestations generally developing during the second half of life. However, a small proportion of patients may present during childhood. PKD is highly associated with liver disease. Hepatic lesions develop in $50-90 \%$ of patients with ADPKD and in all patients with ARPKD (1). In ADPKD proliferative intrahepatic biliary lesions resulting in discrete cyst formation are characteristic. In ARPKD the lesions are variable and consist of proliferation and dilatation of intra- and extrahepatic bile ducts ("ductal ectasia"), and periportal fibrosis as well. The clinical course of the associated liver disease, 
is generally mild in ADPKD and much more severe in patients with ARPKD and may include cholangitis, portal hypertension, and ultimately liver failure (3-5). Genes responsible for human ARPKD and ADPKD have been localized $(6,7)$. In addition the ADPKD gene has been identified in part (7).

Studies into the pathophysiology of PKD have largely focused on the renal lesions using a variety of in vivo and in vitro experimental models (8). Such studies demonstrate that two basic criteria are necessary for renal tubular cyst formation: 1 ) increased tubular epithelial cell proliferation and 2) altered transtubular fluid transport (9-11). The mechanisms responsible for aberrant renal tubular epithelial cell growth are not known. Recent reports suggest a role for abnormal regulation and/or activation of the TGF $\alpha / E G F / E G F-R$ axis $(8,12-17)$. It has been theorized that the presence of mitogenic quantities of TGF $\alpha$ and/or EGF-like peptides in cyst fluid coupled with aberrant apical tubular epithelial expression of EGF-R may drive an autocrine/paracrine cycle of cellular proliferation.

In contrast to the focus on renal pathophysiology in $\mathrm{PKD}$, little is known about the pathophysiology of the hepatic lesions. Studies at the cellular level have been hampered by the low availability of human hepatic tissue and the lack of an animal model. Recently we reported a new spontaneous mutation in Balb/c mice which is a new model of human ARPKD, the BPK strain (18). In BPK mice, renal cystic lesions are associated with intra- and extrahepatic hyperplastic lesions of the biliary tract. The disease is transmitted in an autosomal recessive pattern and leads to terminal renal failure and death in affected animals at the age of 1 mo. The demonstrated hyperplastic abnormalities in both renal and biliary epithelium makes this new strain a good model for the study of dual organ cellular pathophysiology of human ARPKD. Studies were therefore undertaken to establish a cellular model of the abnormal growth regulation of biliary epithelia in murine ARPKD.

\section{METHODS}

Animals. All experiments were approved by the Institution Animal Use and Care Committee. Throughout the experiments we have maintained stable colonies of wild-type Balb/c control mice (Jackson Laboratories) and Balb/c BPK mice. The BPK strain expresses PKD in an autosomal recessive pattern and arose from a spontaneous mutation in 1985 in an otherwise healthy Balb/c colony at the National Institutes of Health. The BPK strain has been maintained as an inbred strain at the University of Washington since 1990. Recently we reported the presence of hepatic as well as renal lesions in these mice (18). In the current experiments 15-25-d-old offsprings from wild-type matings served as controls, whereas affected BPK animals of the same age were obtained from matings of known heterozygotes for the BPK trait. The age group was chosen such that affected mice can be readily identified by physical examination while terminal renal failure is not yet present. Affected mice demonstrated enlarged kidneys as well as macroscopically dilated extrahepatic bile ducts.

Culture medium. Two types of media were initially used in culture of biliary epithelium. Eagle's minimal essential me- dium was supplemented with $10 \%$ fetal calf serum, $20 \mathrm{mM}$ HEPES, $2 \mathrm{mM}$ L-glutamine, $100 \mu \mathrm{g} / \mathrm{mL}$ streptomycin sulfate, and $100 \mathrm{IU} / \mathrm{mL}$ penicillin (19). The second medium consisted of equal volumes of Dulbecco's modified Eagle's medium and Ham's F-12 supplemented with HEPES (10 mM), sodium bicarbonate $13.4 \mathrm{mM}(15 \mathrm{~mL}, 7.5 \%$ per $\mathrm{L})$, glutamine $(2 \mathrm{mM})$, transferrin $\left(6.2 \times 10^{-8} \mathrm{M}\right)$, insulin $\left(2.7 \times 10^{-8} \mathrm{M}\right)$, triiodothyronine $\left(2 \times 10^{-9} \mathrm{M}\right)$, hydrocortisone $\left(2.9 \times 10^{-8} \mathrm{M}\right)$, selenic acid $\left(6.8 \times 10^{-9} \mathrm{M}\right)$, prostaglandin $\mathrm{E} 1\left(7.1 \times 10^{-8} \mathrm{M}\right)$, penicillin $(50 \mathrm{U} / \mathrm{L})$, streptomycin sulfate $(50 \mu \mathrm{g} / \mathrm{mL})$ and nystatin $(50 \mathrm{U} / \mathrm{mL})$. Because the two media gave equal results and because serum would interfere with the intended studies, we used the serum-free medium as BM throughout the current study.

Preparation of culture dishes. Explants were grown on either coated or uncoated 35-mm plastic culture dishes (Falcon, Oxnard, CA). Coating was performed with either Vitrogen-100 (Celltrix, Palo Alto, CA), or with Matrigel (Collaborative Research, Lexington, MA) to determine the most reproducible culture conditions. Vitrogen was used after dilution at $4^{\circ} \mathrm{C}$ with equal volumes of culture medium. Matrigel was used according to the instructions of the manufacturer. Dishes were coated with approximately $100 \mu \mathrm{L}$, placed in the incubator at $37^{\circ} \mathrm{C}$ for $30 \mathrm{~min}$, then filled with $2 \mathrm{~mL}$ culture medium and kept at $37^{\circ}$, $5 \% \mathrm{CO}_{2}$ for use the same day. In preliminary studies Vitrogen coating gave the best results in terms of colony growth, viability, and cellular morphology and was therefore utilized for all of the subsequent studies. For electron microscopy, explants were grown on Vitrogen-coated $22 \times 22-\mathrm{mm}$ coverslips placed in $35-\mathrm{mm}$ culture dishes. Growth and $\left[{ }^{3} \mathrm{H}\right]$ thymidine incorporation studies were performed on explants grown on Vitrogen coated $10 \times 10-\mathrm{mm}$ coverslips placed in $35-\mathrm{mm}$ culture dishes.

Common bile duct explantation and primary cultures. Mice were killed by decapitation and laparotomy was performed under sterile conditions. The common bile duct was carefully dissected from extraneous tissue and from the pancreatic duct. The common bile duct was transsected proximally at the origin of the cystic duct and distally near the choledochoduodenal junction, immediately placed into ice-cold culture medium, and transferred into a laminar flow hood.

Under the stereomicroscope the duct was then cut into $0.2-\mathrm{mm}^{2}$ explants. Each control duct thus provided approximately six explants, while markedly enlarged BPK ducts provided approximately 30 explants for culture. Explants were transferred to fresh medium-free culture dishes and incubated overnight at $37^{\circ} \mathrm{C}, 5 \% \mathrm{CO}_{2}$ to permit attachment. The next morning $2 \mathrm{~mL}$ of culture medium were gently added to each dish and subsequently changed every $2 \mathrm{~d}$.

Immunohistologic characterization. The presence of specific epithelial cell markers was tested on both intact tissue and cultured cells which grew from cultured explants using: 1) a rabbit polyclonal antibody against human cytokeratin which previously was shown to bind specifically to murine biliary epithelial cells (Accurate Chemical and Scientific Corp., Westbury, NY, no. ax 1698) (18) and 2) lectin DBA which also showed specific binding to biliary epithelium in preliminary studies. Monoclonal anti-vimentin antibody (Bio Genex, San 
Ramon, CA) staining was used as a marker for fibroblasts. Immunohistology was performed using our previously described methods (20).

Bile ducts from control mice were rapidly fixed in $3.5 \%$ parafomaldehyde ( $\mathrm{pH} \mathrm{7.4)}$ for $30 \mathrm{~min}$ at $4^{\circ} \mathrm{C}$. Fixed tissue was then washed, dehydrated through a graded acetone series, and infiltrated and embedded in Immunobed plastic embedding medium (Polysciences, Warrington, PA). Immunobed sections ( $3 \mu \mathrm{m}$ each) were etched with alcoholic $\mathrm{NaOH}$, trypsinized, and incubated overnight at $4^{\circ} \mathrm{C}$ with biotinylated DBA $(6.25 \mu \mathrm{g} / \mathrm{mL})$ or after blocking with normal goat serum (1:50) with anticytokeratin antibody $(1: 250)$ or with antivimentin. This was followed for DBA by aviden peroxidase (1:500) for 90 minutes, for the cytokeratin antibody by sequential incubations with bridging goat anti rabbit $\operatorname{IgG}(1: 40)$ for $90 \mathrm{~min}$ and rabbit peroxidase-anti-peroxidase complex $(1: 100)$ for $45 \mathrm{~min}$, and for the anti-vimentin monoclonal by biotinylated anti-mouse $(1: 200)$ for $90 \mathrm{~min}$ and avidin peroxidase $(1: 500)$ for $90 \mathrm{~min}$. Sections were then stained with diaminobenzidine $0.05 \%$, hydrogen peroxide $0.01 \%$. Cells which were identified as outgrowth from cultured explants were stained after first passage. Multiple primary cultures grown for $10 \mathrm{~d}$ were incubated in $0.25 \%$ trypsin, $0.1 \%$ EDTA for $30 \mathrm{~s}$ and after aspiration of the supernatant for another $10 \mathrm{~min}$ at $37^{\circ} \mathrm{C}$, $5 \% \mathrm{CO}_{2}$. The cells were then harvested, washed, seeded on multiwell microscope glass slides, and cultured for $48 \mathrm{~h}$. The slides were then fixed in methanol $\left(-20^{\circ} \mathrm{C}\right)$ for $10 \mathrm{~min}$ and dried. Staining was performed with the same antibodies as given for intact tissue. Primary antibody was applied for $1 \mathrm{~h}$, and secondary antibody and peroxidase for $30 \mathrm{~min}$ each. This was followed by diaminobenzidine staining as described for intact tissue.

Electron microscopy. Transmission electron microscopy was performed on both intact bile ducts and cultured biliary epithelial cells from BPK and control animals. Common bile ducts were fixed in $2 \%$ paraformaldehyde, $2.5 \%$ glutaraldehyde for $2 \mathrm{~h}$ at $4^{\circ} \mathrm{C}$ and postfixed in $0.5 \% \mathrm{O}_{\mathrm{s}} \mathrm{O}_{4}$ for $1 \mathrm{~h}$ at $4^{\circ} \mathrm{C}$, then dehydrated through a series of graded acetone and infiltrated and embedded in Medcast (Ted Pella Inc., Redding, CA). Primary cell cultures grown on Vitrogen-coated glass coverslips were fixed in $1 \%$ paraformaldehyde, $1.25 \%$ glutaraldehyde for $2 \mathrm{~h}$ at $4^{\circ} \mathrm{C}$ and postfixed in $1 \% \mathrm{O}_{\mathrm{s}} \mathrm{O}_{4}$ for $30 \mathrm{~min}$ at $4^{\circ} \mathrm{C}$, then dehydrated through graded ethanols and infiltrated and embedded in Medcast. Ultrathin sections were mounted on copper mesh grids and stained with uranylacetate and lead citrate.

Assessment of mitogenic activity. The mitogenic activity of control and BPK-derived cell cultures was quantitavely assessed using serial colony size measurements and by $\left[{ }^{3} \mathrm{H}\right]$ thymidine incorporation assay. Colony drawings made using a $\mathrm{CK}_{2}$-TRC-2 Olympus inverted microscope with a $\mathrm{BH}_{2}-\mathrm{DA}$ drawing attachment were analyzed using computer-assisted morphometry (Sigmascan). Colony size was measured with 99\% reproducability. Colony growth curves were prepared using daily surface area measurements of control $(n=36)$ and BPK ( $n=19)$-derived primary cell cultures. In addition the mitogenic effect of various polypeptide growth factors was assessed by serial surface area measurements and by a $\left[{ }^{3} \mathrm{H}\right]$ thy- midine incorporation assay as follows. Control and BPKderived primary cell cultures were grown on Vitrogen-coated glass coverslips in BM. After $6 \mathrm{~d}$ of culture the media were replaced by BM, with or without supplementation with one of the following polypeptide growth factors: human IGF-I and -II (25 ng/mL, U.S. Biochemical Corp., Cleveland, Ohio), mouse EGF (20 ng/mL, Sigma), bovine aFGF (12 ng/ml, Sigma), human TGF $\beta$ (2.5 ng/mL, Collaborative Research Corp., Bedford, MA), human HGF (20 ng/mL, Collaborative Research Corp.), and human recombinant $\mathrm{KGF}(12 \mathrm{ng} / \mathrm{mL}$, a generous gift from Dr. Stuart A. Aaronson, Bethesda, MD) (21). Each experimental group consisted of 28 primary cultures.

The effect of serum and growth factor supplementation over basal growth was assessed by both surface area increase during the first $24 \mathrm{~h}$ and by $\left[{ }^{3} \mathrm{H}\right]$ thymidine incorporation after this 24-h incubation. [ $\left.{ }^{3} \mathrm{H}\right]$ Thymidine $(5 \mu \mathrm{Ci} / \mathrm{mL})$ was added to freshly prepared basal or growth factor-supplemented medium. After $6 \mathrm{~h}$ of incubation the coverslips were transferred to scintillation vials and washed with $10 \%$ trichloracetic acid. The cells were then dissolved in Protosol (DuPont, Wilmington, DE) and mixed with Aquassure scintillation cocktail (DuPont). Counts were expressed as desintegrations, $10^{-2} / \mathrm{min}$ $\left(\mathrm{dpm} \cdot 10^{-2}\right)$ and related to the surface area of the colony at the start of the $\left[{ }^{3} \mathrm{H}\right]$ thymidine incubation $\left(\mathrm{dpm} \cdot 10^{-2}\right)$. To visualize light microscopically the distribution of mitogenic activity in individual colonies, we used a 9-h nocodazole $(0.2 \mu \mathrm{g} / \mathrm{mL})$ induced arrest of mitosis before fixation.

Statistics. Data are expressed as means and SD. Differences between growth factor supplemented growth and basal growth were analyzed by unpaired two-tailed $t$ test. Interactions of growth factor effects and strain effects were tested by analysis of variance.

\section{RESULTS}

\section{Explantation and Primary Culture Conditions}

In all BPK mice fusiform dilatation of the entire extrahepatic biliary tract was seen in association with renal cystic disease (18). The outer diameter of the common bile duct was increased in all cases compared with control values (250-1500 $\mu \mathrm{m}$ versus $<200 \mu \mathrm{m}$ ).

The technique of stereomicroscopic fragmentation of the explants did not allow standardized sizing of cultured fragments. The optimal tissue fragment size was approximately 0.2 $\mathrm{mm}^{2}$. Smaller pieces yielded inconsistent culture results. For adequate attachment of the explants to the culture dishes, a collagen coating was indispensable. The attachment efficiency was $90 \%$ for Vitrogen-100 and Matrigel-coated dishes alike and less than $10 \%$ for uncoated dishes. Explants cultured on coated dishes formed an expanding cellular outgrowth in $90 \%$ of cases, which was first noticable after $2 \mathrm{~d}$ of culture. This plating efficiency was not different for Vitrogen-100- and Matrigel-coated dishes. With continuing growth, better results were obtained with Vitrogen-100 where cellular outgrowth was consistently homogenous during $10 \mathrm{~d}$ of culture.

In contrast, cultures grown on Matrigel for more than $5 \mathrm{~d}$ occasionally formed cell-free patches in initially homogenous cell colonies. This was interpreted to be due to the fragility of 
the substratum and the early breakdown of the coating. Vitrogen-100 coating was therefore used for the current studies. In preliminary studies two different types of culture media were compared. The serum-supplemented and the serum-free media produced similar culture results in terms of attachment, plating efficiency, colony growth, and cell density up to $10 \mathrm{~d}$ of culture. Based on these findings and on the requirement of defined culture conditions for the intended experiments on cell growth, we used the serum-free medium as BM throughout the current experiments.
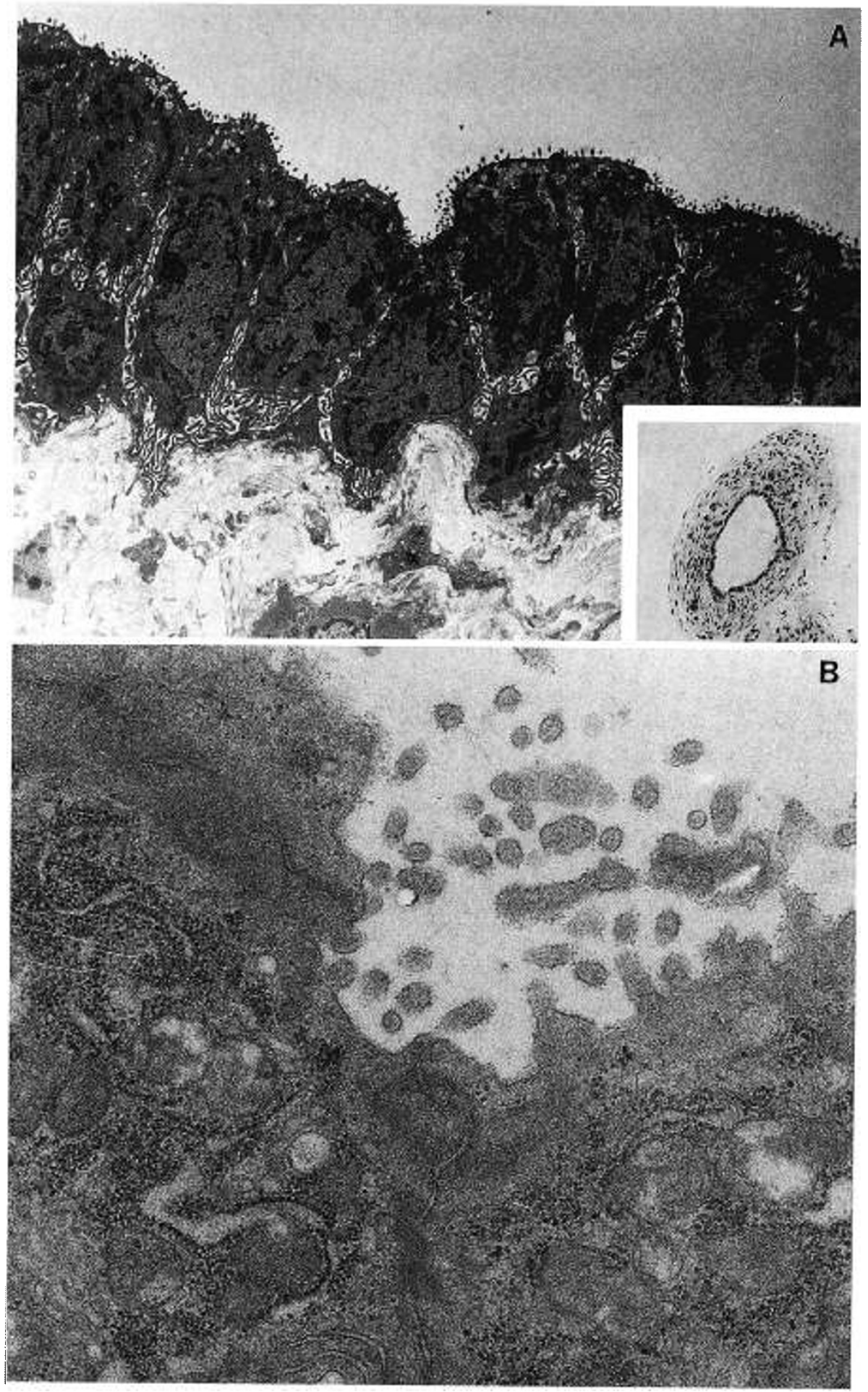

Figure 1. Common bile duct epithelium before culture. $A$, Inset: Overview of an intact undilated common bile duct (hematoxylin, $\times 200$ ). Transmission electron microscopy. Epithelial lining of a dilated common bile duct from a 30-d-old BPK mouse. The cell features are undistinguishable from control ductal epithelium including superficial microvilli, apical secretion vesicles, extensive basolateral infoldings, and an intact basement membrane $(\times 6000)$. B, At higher magnification rough endoplasmatic reticulum with ribosomes as well as free ribosomes can be identified. Apically tight intercellular junctions including desmosomes can be identified $(\times 32000)$. 


\section{Characterization of the Cells}

Cells in and on the primary explants. Before microsurgical dissection, the explants consisted of ducts lined by an epithelial monolayer and surrounded by connective tissue (Fig. 1). In some cases explanted bile ducts were attached to pancreatic and/or to fatty tissue. This could clearly be identified and removed using the stereomicroscope. Only "clean" ducts were used for the culture experiments. The duct walls of dilated bile ducts demonstrated cellular profiles that were not different from normal bile ducts other than an increased number (not density) of epithelial cells. Ultrastructurally the dilated ducts were lined by intact cuboidal epithelium with an intact microvillar surface. Apical tight junctions gave way to complex interdigitations of the lateral cell membranes. Cytoplasmic organelles were dispersed throughout the cell. The underlying basement membrane was intact and of normal caliber and underlayed by collagen and fibroblasts with an active endoplasmatic reticulum. The ultrastructural morphology of explants did not differ from controls.

During culture the explants were covered entirely by a single layer of cuboidal epithelial cells (Fig. 2). These cells had ultrastructural characteristics much like those seen in vivo (Fig. 1). Unlike the epithelium in vivo no basement membrane could be identified at this stage. The underlying tissue consisted of a loose stroma with ultrastructurally viable stromal cells. During culture multiple ductular structures could be observed in most explants. The cells lining these ducts invariably had the ultrastructural appearance of epithelial cells not different from the explant covering cells in Figure 2.

Cellular outgrowth from the primary explants. Cellular outgrowth was first seen after $3 \mathrm{~d}$ of culture at the edges of most explants (Fig. 3). This outgrowth expanded progressively and developed into a dense confluent cell colony in which the cell density was homogenous up to $10 \mathrm{~d}$ of culture (Fig. 4). Fibroblast-like cells were never seen. Two different growth patterns were recognized in these cell colonies. The outer rim of the colony with a width of approximately 20 cells exhibited a relatively low cell density and a high mitogenic activity as illustrated by the nocodazole-induced arrest of mitosis (Fig. 5). The central area of the cell colonies was made up of densily packed cells with low mitogenic activity.

Ultrastructurally a uniform sheet of cells could be identified. Cultured cells formed tight monolayers with the characteristics of polarized epithelia including numerous apical microvilli, tight junctions, extensive intercellular digitations, and the apical distribution of secretory granules and mitochondria (Fig. 6).

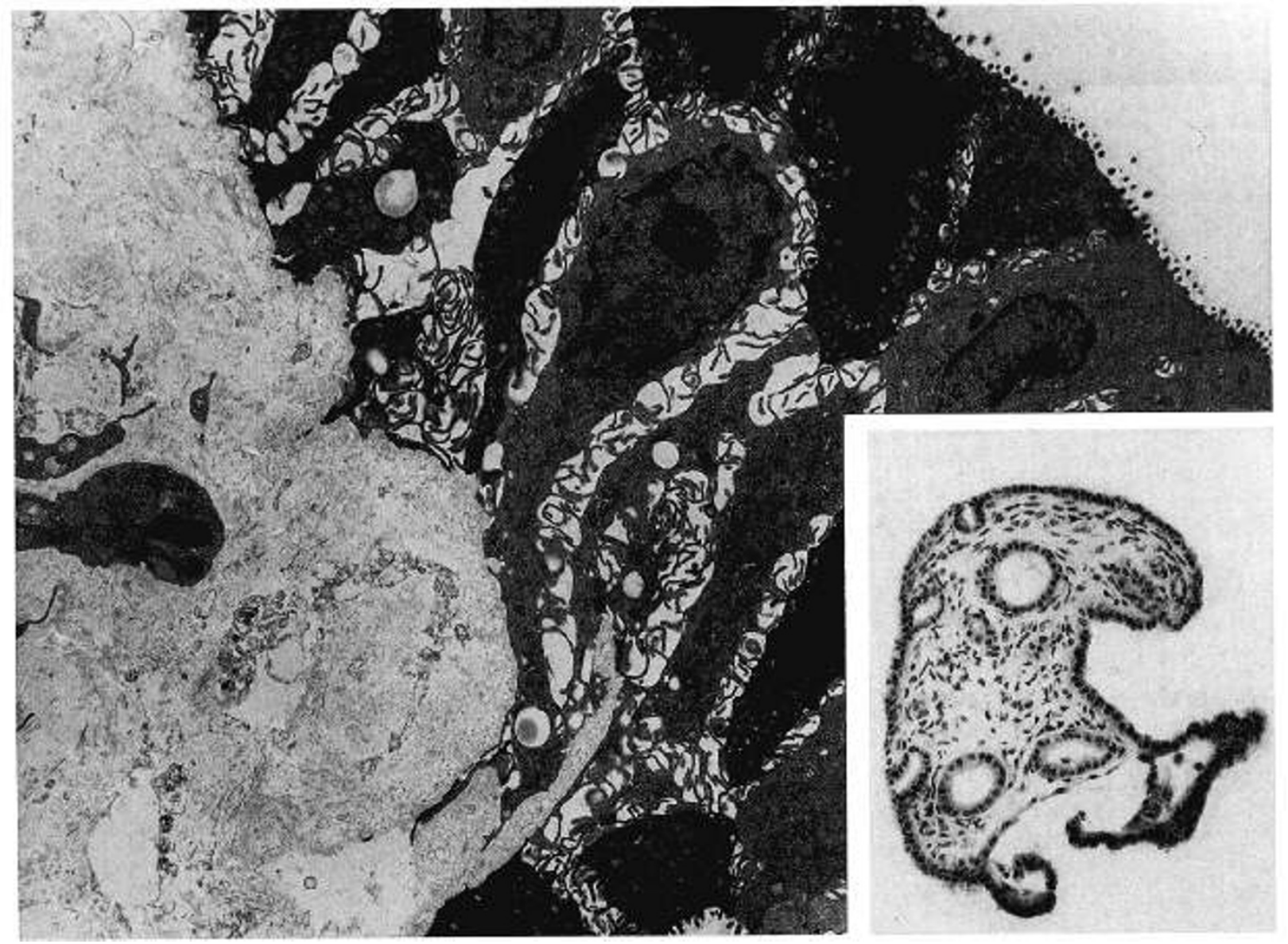

Figure 2. Common bile duct explant cultured for $7 \mathrm{~d}$. Inset: Overview demonstrating the complete coverage of the explant by a dense epithelium as well as the presence of multiple ductular structures within a loose and apparently viable stroma (hematoxylin, $\times 100$ ). Transmission electron microscopy. Epithelial characteristics include apical microvilli, tight junctions, and extensive intercellular digitations. Note the reduced number of secretary granules and the absent basement membrane as compared to the in vivo epithelium shown in Figure $1(\times 8000)$. 


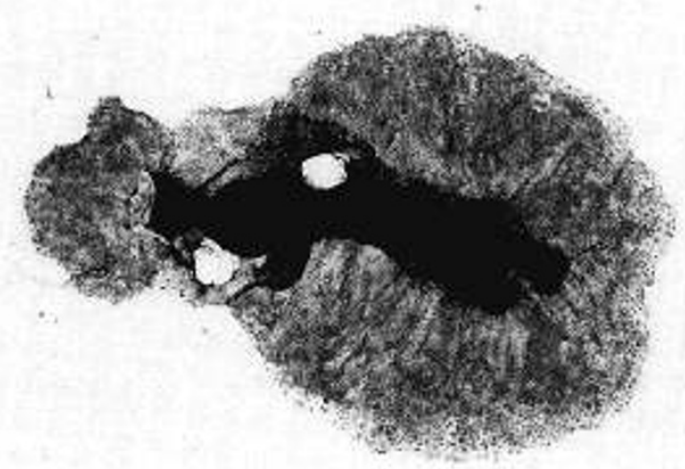

Figure 3. Representative example of a tightly confluent cellular outgrowth from a common bile duct explant (dark central area) cultured for $3 \mathrm{~d}$ in basal medium (hematoxylin, $\times 50$ ).

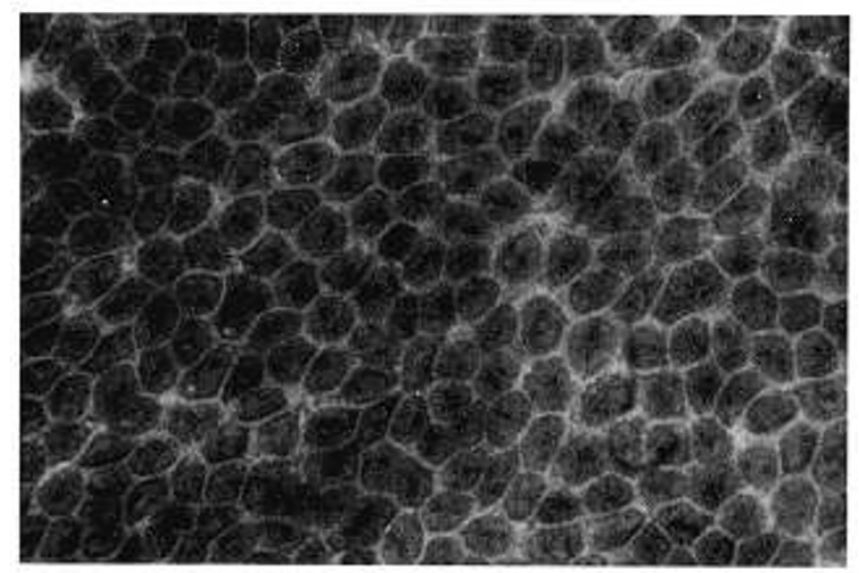

Figure 4. Primary epithelial cell culture from a common bile duct explant cultured for $10 \mathrm{~d}$ in basal medium. Note the homogeneity and high density of the epithelial monolayer (hematoxylin, $\times 300$ ).

Compared with the intact biliary epithelium, the cultured cells were slightly more spread and exhibited no basement membrane at this stage.

Immunocytochemical staining revealed specific binding of anti-cytokeratin antibody to the apical cell membrane of biliary epithelial cells in intact tissue (Fig. 7) as well as to the cultured cells in a delicate filamentous pattern (Fig. 8). Similarly DBA staining revealed specific apical binding to biliary epithelial cells in vivo and positive staining of the cultured cells. Biliary epithelial cells of intact tissue as well as cultured cells did not express vimentin.

\section{Cellular Growth Studies}

Linearity of colony growth up to $10 \mathrm{~d}$ of culture under basal conditions was demonstrated in both BPK- and control-derived cell colonies (Fig. 9). Basal growth of BPK derived cells was not different from controls.

Cellular growth was assessed by measurement of: l) 6-h $\left[{ }^{3} \mathrm{H}\right]$ thymidine uptake and 2) 24-h colony size increments. Data are expressed relative to colony size. These two parameters correlate well when measured simultaneously in individual cell colonies grown in basal medium $(r=0.75)$. Because the size of individual colonies varied considerably we wondered

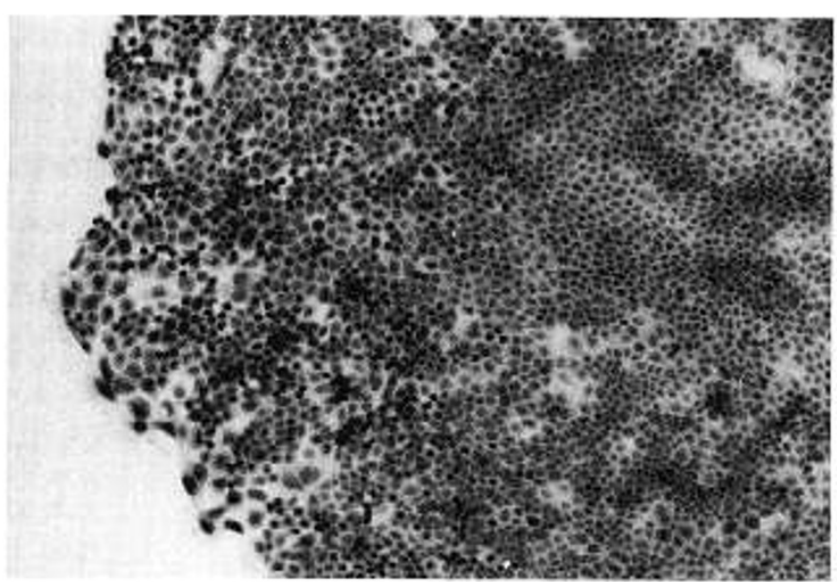

Figure 5. Homogeneous epithelial monolayer cultured for $7 \mathrm{~d}$. Mitogenic activity (visible as dark nuclear chromatin aggregates) is confined to the periphery of the colony. For better visualization, these cells were arrested in mitosis for $9 \mathrm{~h}$ using nocodazole $(0.2 \mu \mathrm{g} / \mathrm{ml})$ incubation (hematoxylin, $\times 50$ ).

whether size is a determinant of colony growth. Under basal medium conditions no such correlation could be demonstrated between colony size and percent cellular growth as assessed by either thymidine uptake or colony size increments. The effects of individual growth factors on $\left[{ }^{3} \mathrm{H}\right]$ thymidine uptake are presented in Table 1 . The results of two sets of experiments are presented separately. Compared with uptake under BM conditions, we found a stimulatory effect of over $130 \%$ for EGF, $\mathrm{KGF}$, and aFGF in cells derived from both BPK and control mice. TGF $\beta$ significantly inhibited the thymidine uptake of both cell populations ( $61 \%$ of basal uptake). HGF and IGF-I inhibited the thymidine uptake to a lesser extent and in control cells only. The proliferative response to exogenous EGF was significantly different for BPK and control cells. This observation was later confirmed by the second set of experiments. BPK-derived cells demonstrated a higher proliferative response to EGF than control cells (mean increase over BM growth for BPK 239\% and for control 131\%, $p<0.001$ ). A similar pattern of growth factor-induced proliferative responses was noted when measuring colony size increments (Table 2). This parameter appeared to be less sensitive than the thymidine uptake assay.

\section{DISCUSSION}

We have recently reported a new murine model of ARPKD expressed in the Balb/c BPK/BPK mouse strain (18). In affected animals both renal tubular and biliary intra- and extrahepatic epithelial hyperplasia were early features of disease as in human ARPKD. We noted that this dual organ epithelial hyperplasia preceded the overall disruption of normal organ architecture that is characteristic of more advanced disease stages. Our current data on in vitro growth characteristics of biliary epithelial cells from BPK mice may therefore reflect early mechanisms involved in the development of hepatic lesions in PKD.

Our system of primary cultures of extrahepatic biliary cells carries several potential advantages over culture systems based on cell isolation from hepatic tissue. The relative simple structure of the common bile duct permits isolation by microsurgery 

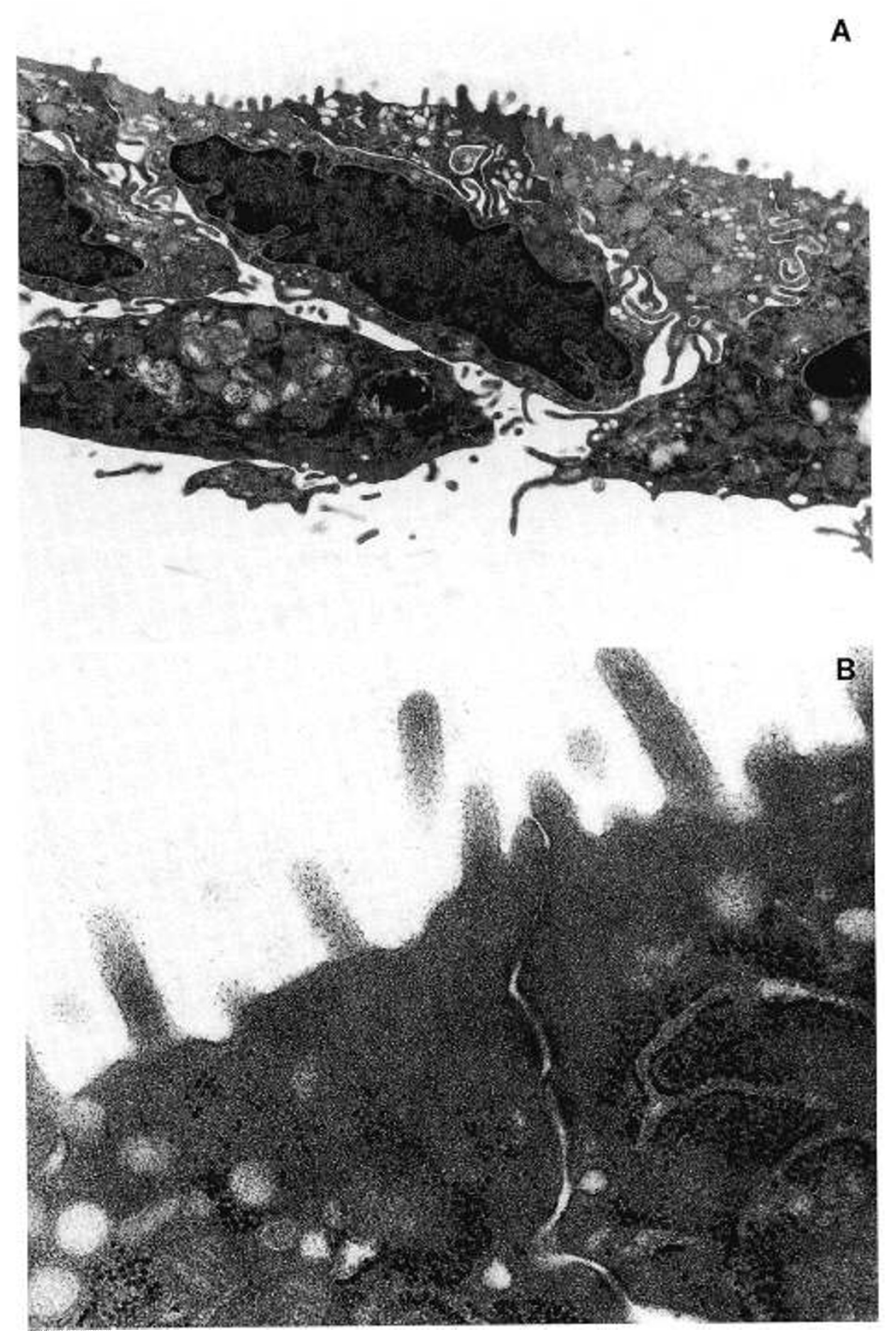

Figure 6. Ultrastructural characteristics of a cellular monolayer cultured from a common bile duct explant derived from a 20-d-old Balb/C control mouse and cultured for $1 \mathrm{wk}$. A, Overview, featuring elongated cells with a rough apical surface, microvilli, extensive intercellular digitations, apical secretory vesicles, lysosomes, mitochondria, and large nuclei with indentations and a regular chromatine pattern $(\times 18750)$. B , Rough endoplasmatic reticulum with ribosomes as well as free ribosomes can be identified at higher magnification. Tight apical cell-cell contact includes desmosomes $(\times 83500)$.

only. The excellent homogeneity of the obtained epithelial cell population makes further isolation steps unnecessary. This prevents the potential hazard of unwanted selection of epithelial cell subsets by stringent isolation procedures. Moreover, surgical isolation allows straightforward matching of control cells. The confounding effect of isolation steps mandatory for whole organ-derived cell suspensions can be omitted. Inasmuch as such steps are based on physical and biochemical cell properties, they may act differently on control and affected cells, consequently complicating the matching process.

Biliary epithelial cells have been isolated and cultured by others from either the intrahepatic biliary tract or the gallbladder from various animal species $(19,22-24)$. None of these methods could be used in the current study. The reported methods necessary for isolation and consequent propagation of biliary cells from liver homogenates potentially affect the 


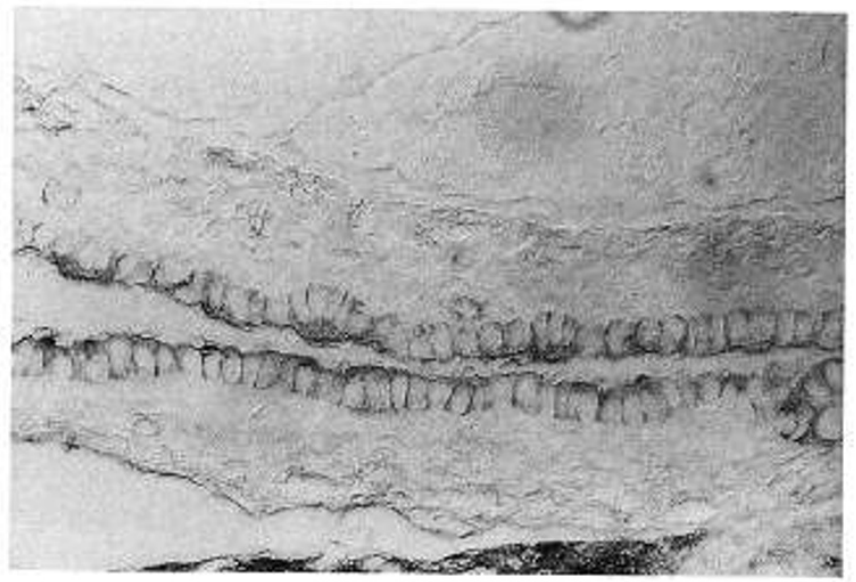

Figure 7. Longitudinal section of a normal common bile duct stained with a polyclonal anticytokeratin antibody (diaminobenzidine, $\times 200$ ).

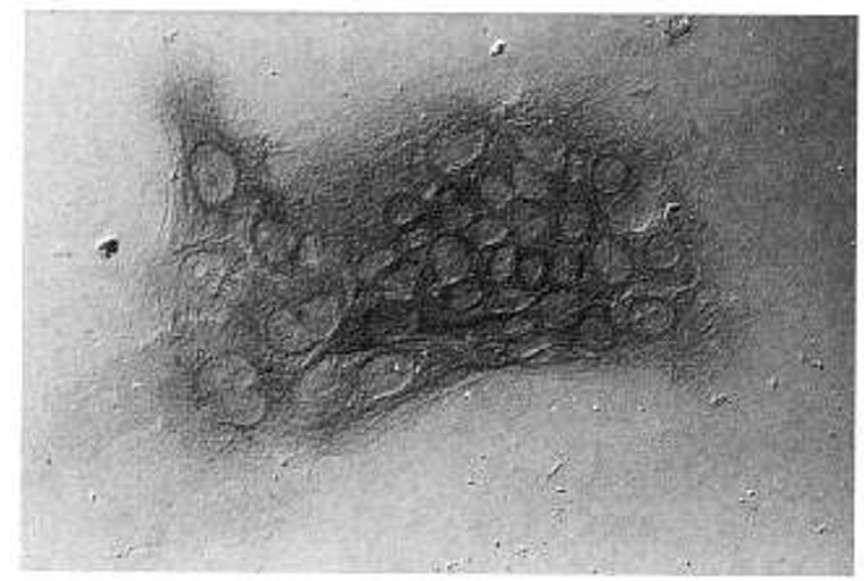

Figure 8. First passage biliary epithelial cells stained with polyclonal anti human cytokeratin antibody (diaminobenzidine, $\times 200$ ).

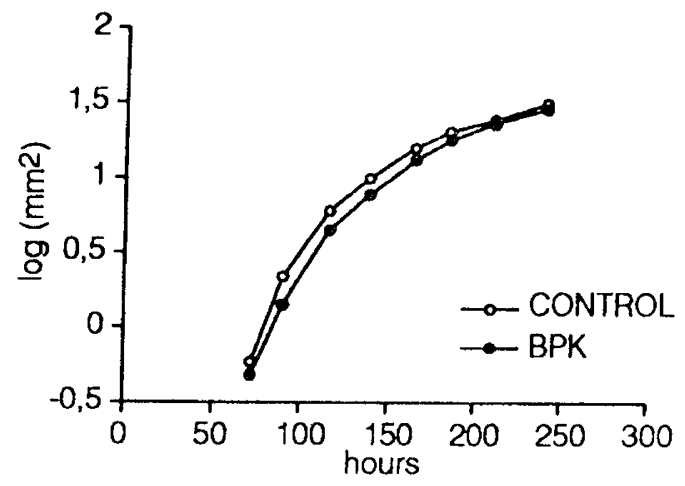

Figure 9. Surface area growth pattern during $10 \mathrm{~d}$ of culture of primary cell colonies derived from common bile duct explants form Balb/C BPK and control baby mice of $20-25 \mathrm{~d}$ of age.

characteristics of the obtained cell population through less than perfect purification and through selection. Methods using the gallbladder as an epithelial cell source could not be used in the current study because of its small size in mice and foremost because the gallbladder was the only apparently unaffected part of the biliary tract in the murine disease model.

The linear growth pattern which was maintained up to $10 \mathrm{~d}$ of culture allows the comparison of the growth characteristics of BPK- and control-derived cell colonies. The two parameters
Table 1. The effect of growth factor supplementation on the uptake of $\left.{ }^{3} H\right]$ thymidine by control and BPK cell cultures

\begin{tabular}{|c|c|c|c|c|c|}
\hline \multirow[b]{2}{*}{ Exp. } & \multirow[b]{2}{*}{ Factor } & \multicolumn{2}{|c|}{ Control } & \multicolumn{2}{|c|}{ BPK } \\
\hline & & $\mathrm{dpm} / \mathrm{mm}^{2}$ & $\begin{array}{l}\text { Percent } \\
\text { of } \mathrm{BM}\end{array}$ & $\mathrm{dpm} / \mathrm{mm}^{2}$ & $\begin{array}{l}\text { Percent } \\
\text { of } \mathrm{BM}\end{array}$ \\
\hline \multirow[t]{4}{*}{1} & $\mathrm{BM}$ & 39 (17) & & $29(16)$ & \\
\hline & EGF & $46 \quad(17)$ & 118 & $76(31)^{*}$ & $262 \dagger$ \\
\hline & IGF-1 & $29(12)^{*}$ & 74 & $29(15)$ & 101 \\
\hline & HGF & $29(8)^{*}$ & 75 & 29 (19) & 100 \\
\hline \multirow[t]{6}{*}{2} & $\mathrm{BM}$ & 39 (19) & & $30(24)$ & \\
\hline & EGF & $56(30)^{*}$ & 143 & $65(42) \ddagger$ & $217 \S$ \\
\hline & aFGF & $54(17)^{*}$ & 139 & $40 \quad(29)$ & 133 \\
\hline & $\mathrm{KGF}$ & $61(32)^{*}$ & 156 & $49(30) \ddagger$ & 169 \\
\hline & IGF-2 & 50 & 109 & $30(16)$ & 100 \\
\hline & TGF $\beta$ & $24(18)^{*}$ & 61 & $18(19)^{*}$ & 64 \\
\hline
\end{tabular}

The uptake of $\left[{ }^{3} \mathrm{H}\right]$ thymidine by primary biliary cell cultures derived from BPK and control animals in the presence or absence (BM) of various growth factors. Data from two sets of experiments are presented separately and expressed as mean (SD) desintegrations per minute per surface area of the cell colonies $\left(10^{-2} \mathrm{dpm} / \mathrm{mm}^{2}\right)(n=25-30$ for each data point). The growth factor data are additionally presented relative to the thymidine uptake in defined BM.

${ }^{*} p<0.05$, growth factor $v$ BM.

$\ddagger p<0.001$, growth factor $v s \mathrm{BM}$.

$\S p<0.05$, BPK $v s$ control.

$\dagger p<0.001$, BPK vs control.

Table 2. The effect of growth factor supplementation on 24- $h$ colony growth of control and BPK cell cultures

\begin{tabular}{llrlrr}
\hline & \multicolumn{2}{c}{ Control } & & \multicolumn{2}{c}{ BPK } \\
\cline { 2 - 3 } \cline { 5 - 6 } Factor & Growth & $\begin{array}{c}\text { Percent } \\
\text { of BM }\end{array}$ & & Growth & $\begin{array}{r}\text { Percent } \\
\text { of BM }\end{array}$ \\
\hline BM & $32(17)$ & & $26(11)$ & \\
EGF & $42(14)^{*}$ & 131 & & $42(17)^{*}$ & 157 \\
$\alpha$ FGF & $36(9)$ & 110 & $30(12)$ & 113 \\
KGF & $30(14)$ & 93 & $30(18)$ & 114 \\
HGF & $29(10)$ & 90 & $26(14)$ & 99 \\
IGF-1 & $26(9)$ & 80 & $23(10)$ & 85 \\
IGF-2 & $33(22)$ & 102 & $30(14)$ & 112 \\
TGF $\beta$ & $28(15)$ & 87 & $18(8)^{*}$ & 67 \\
\hline
\end{tabular}

Colony growth of primary biliary cell cultures derived from BPK and control animals in the presence or absence of various growth factors. Data are expressed as mean (SD) percent increase of surface area during 24-h observations ( $n=25-30$ for each data point). Growth factor data are additionally presented relative to growth in BM (percent over BM).

${ }^{*} p<.001$, growth factor $v s$ BM.

used in this study to assess colony growth, surface area increment and thymidine uptake, correlate well when measured simultaneously in individual colonies under BM conditions. However, the effect of growth factor supplementation on these two parameters (Table 1) was disparate in some cases. The fact that growth factor effects on colony size were assessed over the first $24 \mathrm{~h}$ of factor supplementation whereas the thymidine uptake was measured during the following $6 \mathrm{~h}$ may explain this apparent disparity.

Because the colony growth curves of BPK-derived cell colonies in serum-free basal medium were not different from controls, we had the opportunity to test the proliferative response of the cells to specific growth factors. Several significant growth factor effects were noted in both BPK and controls. Only EGF repeatedly induced a significantly higher effect in 
BPK-derived cell colonies when compared with controls. The potential biologic significance of the increased sensitivity of BPK-derived biliary epithelial cells to EGF is highlighted by the reported secretion of EGF from the circulation into the bile in an immunoreactive and biologically active form. Moreover, the appearance of intact EGF in bile of suckling rats is severalfold higher than in adult rats (25). In addition cultured bile duct epithelial cells are known to be capable of receptormediated binding and endocytosis of EGF (26).

Such findings parallel data from renal cystogenesis in PKD. Overexpression of the EGF-R and of its messenger RNA has been demonstrated using whole kidney homogenates from both human (12) and murine (13) cystic kidneys. In addition abnormal localization of the EGF-R to the lumenal membrane of renal tubular epithelia in contrast to the normal basolateral localization has been reported for human as well as murine PKD (14). The biologic significance of these findings is demonstrated by the report of mitogenic concentrations of EGF in cyst fluid (15), the increased EGF induced mitogenic response of human cyst-derived cells (16), and the cystogenic properties of EGF in metanephric organ culture (27) and in cultures of normal kidney cells in collagen gel (28).

In conclusion we report a reproducable serum-free cell culture system in which minimal selection by isolation procedures and excellent homogeneity of the cell colonies provide optimal conditions for the study of normal and abnormal biliary epithelial cell growth in murine PKD. The demonstration of increased sensitivity of BPK-derived cells specifically to the proliferative effect of EGF contributes to the hypothesis that epithelial hyperproliferation is an underlying pathogenic mechanism of the renal and biliary lesions in PKD and that abnormal regulation of the EGF/EGF-R is involved in this process.

Acknowledgments. The authors gratefully acknowledge the technical advise of Dr. Sum P. Lee and Dr. Dolphine Oda (Departments of Oral Biology and Medicine, University of Washington, Seattle, Washington) and the technical assistance of Rob Willemsen (Department of Clinical Genetics, Erasmus University, Rotterdam, The Netherlands).

\section{REFERENCES}

1. Welling LW, Grantham JJ 1991 Cystic and developmental diseases of the kidney. In: Brenner B, Rector F (eds) The Kidney. WB Saunders, Philadelphia, pp 1657-1694

2. Churchill DN, Bear JC, Morgan J, Payne RH, McManamon PH, Gault MH 1984 Prognosis of adult onset polycystic kidney disease re-evaluated. Kidney Int 26:190193
3. Picolli DA, Witzleben CL 1991 Disorders of intrahepatic bile ducts. In: Walker WA, Durie PR, Hamilton JR, Walker-Smith JA, Watkins JB (eds) Pediatric Gastrointestinal Disease. Decker, Philadelphia, pp 1124-1140

4. Kaplan BS, Kaplan P 1990 Autosomal recessive polycystic kidney disease. In: Spitzer A, Avner ED (eds) Inheritance of Kidney and Urinary Tract Diseases. Kluwer, Dordrecht, pp 265-276

5. Desmet VJ 1985 Intrahepatic bileducts under the lens. J Hepatol 1:545-549

6. Zerres K, Mücher G, Bachner L, Deschennes G, Eggermann T, Kääriäinen H, Knapp $M$, Lennert T, Misselwitz J, van Mühlendahl KE, Neumann HPH, Pyrson Y, Rudnik-Schöneborn, Steinbicker V, Wirth B and Schärer K 1994 Mapping of the gene for autosomal recessive polycystic kidney disease (ARPKD) to chromosome 6p21cen. Nat Genet 7:429-432

7. European Polycystic Kidney Disease Consortium 1994 The polycystic kidney disease 1 gene encodes a $14 \mathrm{~kb}$ transcript and lies within a duplicated region on chromosome 16. Cell 77:881-894

8. Avner ED, McAteer JA, Evan AP 1990 Models of cysts and cystic kidneys. In: Gardner KD, Bernstein J (eds) The Cystic Kidney. Kluwer, Dordrecht, pp 55-98

9. Grantham JJ, Geiser JL, Evan AP 1987 Cyst formation and growth in autosomal dominant polycystic kidney disease. Kidney Int 31:1145-1152

10. Avner ED 1988 Renal cystic disease. Nephron 48:89-93

11. Wilson PD, Sherwood AC 1991 Tubulocystic epithelium. Kidney Int 39:450-463

12. Klingel R, Dippold W, Störkel S, Meyer zum Büschenfelde KH, Köhler H 1992 Expression of differentiation antigens and growth-related genes in normal kidney, autosomal dominant polycystic kidney disease, and renal cell carcinoma. Am J Kidney Dis 19:22-30

13. Orellana S, Sweeney WE, Neff C, Avner ED 1995. Epidermal growth factor receptor expression is abnormal in murine polycystic kidney. Kidney Int 47:490-499

14. Avner ED, Sweeney WE 1992 Epidermal growth factor (EGF) and altered membrane localization of epidermal growth factor receptor (EGFR) modulate in vitro renal collecting tubule cystogenesis. Pediatr Res 328A(abstr)

15. Horikoshi S, Kubota S, Martin RS, Yoshihiko Y, Klotman EP 1991 Epidermal growth factor expression (EGF) in the congenital polycystic mouse kidney. Kidney Int 39:57-62

16. Wilson PD 1991 Aberrant epithelial cell growth in autosomal dominant polycystic kidney disease. Am J Kidney Dis 17:634-637

17. Wilson PD, Du J, Norman JT 1993 Autocrine, endocrine and paracrine regulation of growth abnormalities in autosomal dominant polycystic kidney disease. Eur J Cell Biol 61:131-138

18. Nauta J, Ozawa Y, Sweeney Jr WE, Rutledge JC, Avner ED 1993 Renal and biliary abnormalities in a new murine model of autosomal recessive polycystic kidney disease. Pediatr Nephrol 7:163-172

19. Oda D, Lee SP, Hayashi A 1991 Long term culture and partial characterization of dog gallbladder epithelial cells. Lab Invest 64:682-692

20. Sweeney WE, Avner ED 1991 Intact organ culture of murine metanephros. J Tissue Culture Methods 13:163-168

21. Rubin JS, Osada H, Finch PW, Taylor WG, Rudikoff S, Aaronson SA 1989 Purification and characterization of a newly identified growth factor specific for epithelial cells. Proc Natl Acad Sci USA 86:802-806

22. Ishii M, Vroman B, LaRusso NF 1989 Isolation and morphologic characterization of bile duct epithelial cells from normal rat livers. Gastroenterology 97:1236-1247

23. LaRusso NF, Hoerl BJ, Vroman BT, Scott RE 1989 Biological characteristics of cultured human gallbladder epithelial cells. Hepatology 10:636(abstr)

24. Vierling JM 1989 Biliary victories: studies of isolated biliary epithelial cells. I Lab Clinical Med 113:663-664

25. Kong W, Koldovsky O, Rao RK 1992 Appearance of exogenous epidermal growth factor in liver, bile and intestinal lumen of suckling rats. Gastroenterology 102:661667

26. Ishii M, Vroman B, Larusso NF 1990 Morphologic demonstration of receptor mediated endocytosis of epidermal growth factor by isolated bile duct epithelial cells. Gastroenterology 98:1284-1291

27. Avner ED, Sweeney WE 1990 Polypeptide growth factors in metanephric growth and segmental nephron differentiation. Pediatr Nephrol 4:372-377

28. Neufeld TK, Douglas D, Grant M, Ye M, Silva F, Nadasdy T, Grantham JJ 1992 In vitro formation and expansion of cysts derived from human renal cortex epithelial cells. Kidney Int 41:1222-1236

29. Nauta J, Sweeney WE, Avner ED 1993 In vitro model of epithelium hyperplasia in murine autosomal recessive polycystic kidney disease (ARPKD). Kidney Int 43:466 